\title{
非富勒烯小分子有机太阳能电池电子受体材料的研究进展
}

\author{
付钰王芳张燕方旭赖文勇* 黄维* \\ (有机电子与信息显示国家重点实验室培育基地 南京邮电大学信息材料与纳米技术研究院＼cjkstart南京 210023)
}

\begin{abstract}
摘要 富勒烯及其衍生物是一类重要的 $n$-型电子受体材料, 在有机太阳能电池器件中发挥了至关重要的作用. 但由于 富勒烯材料吸光波长较窄、亲和能高、溶解性差等, 严重限制了富勒烯作为有机太阳能电池 $n$-型电子受体材料的更广 泛应用和器件性能的进一步提升. 非富勒烯 $n$-型电子受体材料具有能级可调、合成简便、加工成本低、溶解性能优异 等特点, 更重要的是, 此类材料在可见太阳光光谱中比富勒烯及其衍生物材料有更加宽广的吸收范围; 近年来, 受到 越来越多的关注和研究. 本文较为系统地阐述了非富勒烯小分子材料作为有机太阳能电池 $n$-型电子受体材料的研究进 展, 并对其发展前景作了展望.
\end{abstract}

关键词 $n$-型小分子电子受体材料; 宽光谱吸收; 可溶液加工; 有机光伏器件

\section{Research Progress of Non-Fullerene Small-Molecule Acceptor Materials for Organic Solar Cells}

\author{
$\mathrm{Fu}, \mathrm{Yu} \quad$ Wang, Fang Zhang, Yan Fang, Xu Lai, Wenyong* Huang, Wei* \\ (Key Laboratory for Organic Electronics \& Information Displays (KLOEID), Institute of Advanced Materials (IAM), \\ Nanjing University of Posts \& Telecommunications, Nanjing 210023)
}

\begin{abstract}
Bulk heterojunction organic photovoltaics have been the subject of intensive academic interest over the past two decades. Numerous recent efforts have been directed towards this area with the vision of developing next-generation low-cost solar cells. In the field of bulk heterojunction organic photovoltaics, fullerene and its derivatives are an important class of $n$-type electron acceptor materials. However, their disadvantages such as narrow wavelength absorption, high affinity, poor solubility, have severely limited their wide application as electron acceptors for organic solar cells and have largely hampered further improvement of the device performance. Recently, a number of research efforts have been focused on the development of novel non-fullerene $n$-type small-molecule acceptors. Various design rules and interesting new materials have been explored. The non-fullerene $n$-type small-molecule acceptors usually appear to possess lots of attractive advantages, such as adjustable energy levels, facile synthesis, good solubility, low processing cost. More important, when compared to the fullerene and its derivatives, this kind of small-molecule acceptors has wider spectral absorption that allows to absorb more sunlight to generate electricity. Recent breakthroughs rely mostly on the development of novel high-performance acceptor materials and optimization of the device structures. The up-to-date power conversion efficiencies exceeding $4 \%$ with using non-fullerene small-molecule acceptor materials in bulk heterojunction organic solar cells have been achieved. In this review, recent advances of non-fullerene small-molecule $n$-type acceptor materials for organic solar cells are reviewed, including rylene diimide-based acceptors, pentacene-based acceptors, benzothiadiazole-based acceptors, 1,4-diketopyrrolo-[3,4-c]pyrrole (DPP)-based acceptors, fluorene-based acceptors, fluoranthene-fused imide-based acceptors and so on. Meanwhile, the future trends on material design and development have also been discussed. This review on illustrating the influence of the molecular structures and corresponding photovoltaic properties would thus be helpful to further unravel the role of electron acceptors and shed light on exploring efficient $n$-type electron acceptor materials for high performance organic photovoltaic devices.
\end{abstract}

Keywords $n$-type small-molecular acceptors; wide spectral absorption; solution processing; organic photovoltaics

\footnotetext{
*E-mail: iamwylai@njupt.edu.cn; iamwhuang@njupt.edu.cn

Received November 8, 2013; published January 3, 2014.

Project supported by the National Key Basic Research Program of China (973 Program, Nos. 2014CB648300, 2009CB930601), the National Natural Science Foundation of China (Nos. 20904024, 51173081, 61136003, 61106036), the Natural Science Foundation of Jiangsu Province (Nos. BK20130037, BK2011760), the Nanjing University of Posts and Telecommunications (NUPT) Scientific Foundation (Nos. NY210016, NY212072), the Ministry of Education of China (Nos. 20133223110008, IRT1148), the Priority Academic Program Development of Jiangsu Higher Education Institutions (PAPD), the Six Talent Plan (No. 2012XCL035) and the Qing Lan Project of Jiangsu Province.

项目受国家重点基础研究发展计划项目(Nos. 2014CB648300, 2009CB930601)、国家自然科学基金(Nos. 20904024, 51173081, 61136003, 61106036)、 江苏省自然科学基金(Nos. BK20130037, BK2011760)、南京邮电大学攀登计划(Nos. NY210016, NY212072)、教育部创新基金(Nos. 20133223110008, IRT1148)、江苏高校优势学科建设工程资助项目、江苏省六大人才高峰项目(No. 2012XCL035)和江苏省 “青蓝工程”项目资助.
} 


\section{1 引言}

随着全球能源和环境问题的日益严峻, 太阳能因其 不受地域限制、没有噪音、无污染、利用成本低等特 点 ${ }^{[1]}$, 引起了各国政府的极大重视. 1954 年, 美国的贝 尔实验室成功研制出硅太阳能电池, 开创了光电转换研 究的先河, 之后关于太阳能电池的研究迅速发展. 最初 主要集中于以单晶硅为活性材料的无机太阳能电池. 20 世纪 90 年代又发展了砷化镓、碲化镉以及叠层 GaInP/ $\mathrm{GaAs} / \mathrm{Ge}$ 等器件, 它们由单晶、多晶或非晶薄膜构成. 由于无机太阳能电池制作成本高、生产工艺复杂，而且 窄带隙半导体的严重光腐蚀很大程度上制约了太阳能 发电技术的推广应用. 随着有机半导体领域快速的发 展 $^{[2 \sim 5]}$, 使低成本太阳能发电技术的推广应用成为可能. 与传统硅基及其他无机金属化合物太阳能电池相比, 有 机太阳能电池(organic photovoltaic cells, OPVs) 具有以 下独特优势: (1)有机材料质量轻、柔韧性好; (2)有机材 料易于进行化学结构设计、裁剪和合成, 无资源存量的 限制; (3)器件制备工艺简单, 可采取印刷、喷墨、打印 等溶液加工方法, 制作成本低; (4)易于实现大面积/柔性 器件. 由于上述优势的巨大潜力, 使得有机太阳能电池 成为新一代太阳能电池的重要发展方向 ${ }^{[6]}$.

有机太阳能电池通常采用基于 $p$-型给体材料和 $n$ 型受体材料的 $p-n$ 异质结器件结构 ${ }^{[7]}$. 其工作原理主要 为 $\mathrm{OPV}$ 器件吸收光子产生激子, 扩散到 $p-n$ 异质结表 面, 然后解离形成空穴和电子; 相反极性的载流子(空 穴和电子)通过 $p$-型和 $n$-型通道输运到阴极和阳极后汇 集形成电流, 从而产生电能. $p-n$ 异质结主要包括双层异 质结和本体异质结 $(\mathrm{BHJ})^{[8,9]}$ 两种, 如图 1 所示.

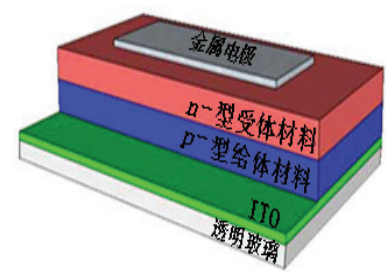

(a) 双层异质结结构

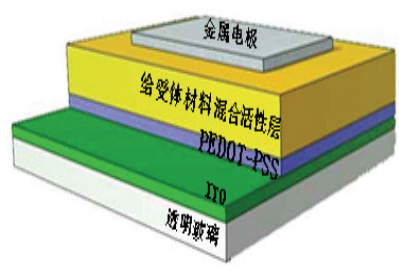

(b)本体异质结结构
图 1 OPV 器件的两种 $p-n$ 异质结结构示意图

Figure 1 Two basic $p-n$ heterojunction structures of OPV devices

20 世纪 80 年代中期以前, 传统的有机太阳能电池 中, 一个单组分有机材料层被夹在两个不同功函数的电 极之间 ${ }^{[10]}$. 在这些单层和单组分的有机太阳能电池中, 电流的产生主要来自于内建电势的 Schottky 势垒型的金 属/有机物接触或电极的功函数的差异, 所以其光伏性 能对于电极的依赖性很强. 这些早期的有机太阳能电池 的性能并不理想. 1986 年 Tang 等 ${ }^{[11]}$ 首次引入给受体结 构的有机双层异质结的概念(如图 1a), 制备了双层有机 太阳能电池, 其转换效率(PCE)达到了 $1 \%$, 这成为有机 太阳能电池的发展里程碑. 这是首次提出了双层异质结 结构的有机太阳能电池, 至今依然是重要的研究方向.
然而, 此结构的有机太阳能电池性能受限于有机材料中 的激子扩散长度(通常为 5 30 nm) ${ }^{[12]}$, 进而激子的扩散 长度又限制了活性层的最大厚度.

为了提高 OPV 器件的转化效率, 最有效的方式就 是扩大激子分离的 $p-n$ 界面, 增强电子与空穴的分离效 果, 进而发展了本体异质结结构(如图 1b). 在这样的结 构中, 受体完全掺杂在给体材料中, 两者充分混合, 扩 大了 $p-n$ 界面, 更有利于激子的分离. 如此, 自由电子 与空穴可以更加高效地输运到相应的电极, 从而产生光 电流. 这样的结构较之双层异质结结构, 其激子分离效 果得到了显著改善 ${ }^{[13,14]}$.

1992 年, Sariciftci 等 ${ }^{[15]}$ 发现了共轭聚合物和富勒烯 $\left(\mathrm{C}_{60}\right)$ 的混合物受光激发作用会产生迅速、高效的光诱导 电子转移. 此后, 富勒烯作为典型的电子受体材料受到 了广泛关注, 并且迅猛发展. 随后, 一系列富勒烯衍生 物被开发出来, 并展示出了良好的电子受体性质, 比如 $\mathrm{PC}_{61} \mathrm{BM}, \mathrm{PC}_{71} \mathrm{BM}$ 等. 迄今为止, Yang 课题组 ${ }^{[16 \mathrm{a}]}$ 使用 $\mathrm{PC}_{71} \mathrm{BM}$ 作为电子受体, 制作了串联叠层 $\mathrm{OPV}$ 器件, 其 最高转化效率已达了 $10.6 \%$, 是目前为止文献报道中叠 层 OPV 器件的最高 PCE; 然而非叠层 OPV 器件最高转 化效率为 $9.2 \%{ }^{[16 b]}$, 但仍然低于 $10 \%$ (单层 OPV 器件效 率大于 $10 \%$ 通常被视为是一个商业规模化应用的先决 条件 ${ }^{[16 \mathrm{c}]}$. 但由于富勒烯及其衍生物材料吸光波长范围 较窄、亲和能高、溶解性差等, 严重制约了富勒烯作为 有机太阳能电池电子受体材料的更广泛应用和器件性 能的进一步提升 ${ }^{[17 ~ 19]}$. 而非富勒烯电子受体材料相对 于富勒烯及其衍生物, 发展比较缓慢. 近年来, 非富勒 烯小分子电子受体材料因为其能级可调、合成简便、制 作成本低、溶解性能优异等吸引了人们越来越多的关注. 更重要的是, 此类材料在可见太阳光光谱中比富勒烯及 其衍生物材料有更为宽广的吸收范围 ${ }^{[20,21]}$. 本文综述了 近年来几类重要的非富勒烯 $n$-型电子受体材料, 其中包 括基于酰亚胺、芴基衍生物、苯噻唑、吡咯并吡咯二酮、 并五苯等新型 $n$-型电子受体材料的最新研究进展.

\section{2 非富勒烯小分子电子受体材料}

\section{1 酰亚胺及其衍生物小分子电子受体材料}

酰亚胺类材料作为电子传输材料在高性能有机场 效应晶体管(OFETs)方面具有重要的应用. 基于此, 人 们对其作为有机太阳能电池非富勒烯 $n$-型电子受体材 料方面的应用产生了浓厚兴趣 ${ }^{[22]}$. 酰亚胺类材料之所 以可以作为替代富勒烯的 $n$-型电子受体材料, 主要是因 为它们优良的吸光特性、较宽的太阳光波谱响应范围、 高的电子迁移率、可调的最高占有分子轨道(HOMO)和 最低末占分子轨道( LUMO) 能级、与富勒烯相当的电子 亲和能, 并且可以通过简易的化学修饰改变在酰亚胺氮 原子上的取代基或修饰酰亚胺的核，而得到一系列具有

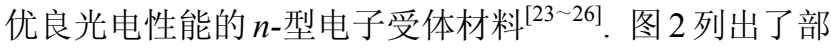


分典型的酰亚胺类小分子 $n$-型电子受体材料的化学结 构. 表 1 列出了酰亚胺类小分子 $n$-型电子受体材料在 OPV 器件中的光伏性能.

其中, 荘酰亚胺(PDI) 类材料是有机太阳能电池最 早研究和最常见的非富勒烯 $n$-型电子受体材料. 然而, 菲酰亚胺及其衍生物在常规有机溶剂中溶解度有限. 这 限制了在制作器件时溶剂的选择, 对一些给体材料的成 膜性造成了很大影响(比如 P3HT ${ }^{[27]}$. 为了克服这样的 影响, Kamm 等 ${ }^{[28]}$ 通过在花酰亚胺的 $2,5,8,11$ 号位置上 引入烷基支链, 合成并研究了一系列芢酰亚胺类有机太 阳能电池电子受体材料(化合物 1 3). 烷基支链的引入 改善了 PDI 溶解性, 尤其在高沸点溶剂中. 而且可以调

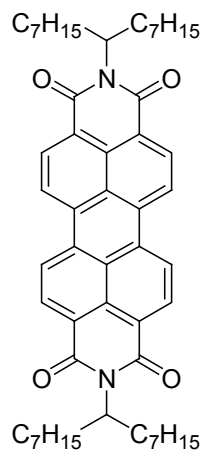

1

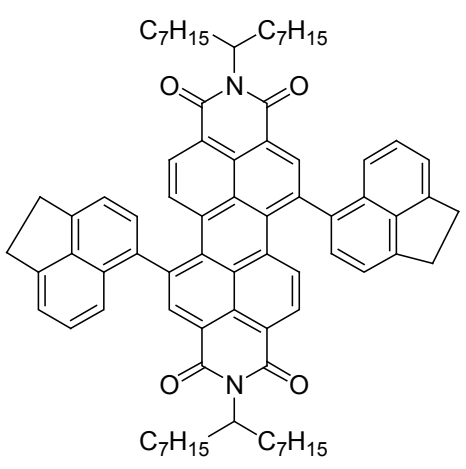

5

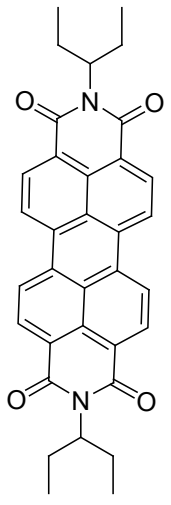

2

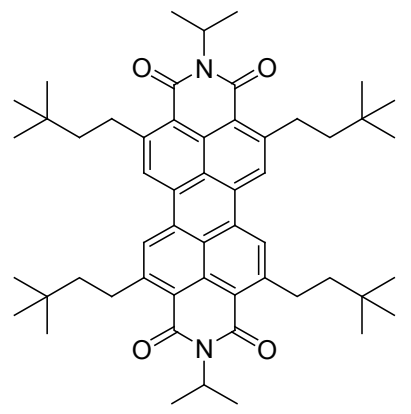

3<smiles>O=C1c2ccc3c4ccc5c6c(ccc(c7ccc(c2c37)C(=O)N1c1ccccc1)c64)C(=O)N(c1ccccc1)C5=O</smiles>

7

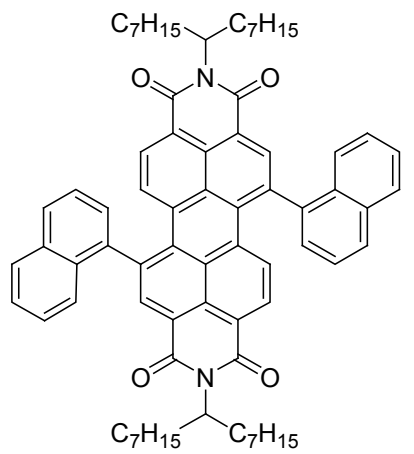

4<smiles>CCCCCc1ccc(C(C)(C)C)cc1N1C(=O)c2ccc3c4ccc5c6c(ccc(c7ccc(c2c37)C1=O)c64)C(=O)N(c1cc(C(C)(C)C)ccc1Br)C5=O</smiles>

6

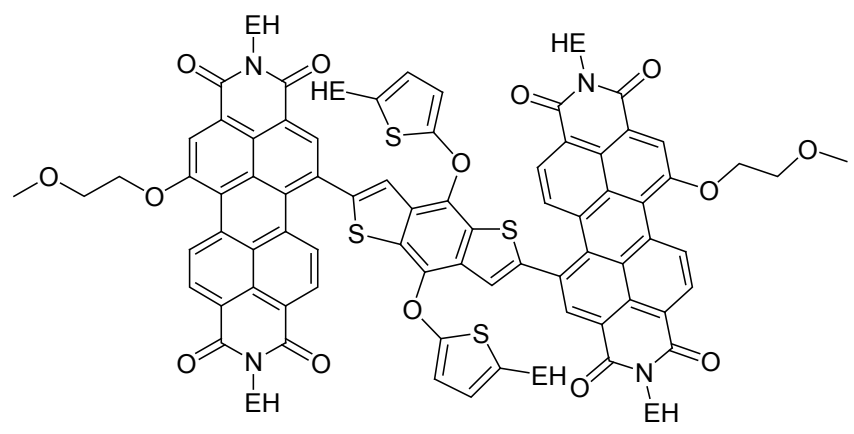

9b

$\mathrm{EH}=$ ethylhexyl, 乙基己基 
<smiles>[R]N1C(=O)c2ccc3c4c(Oc5ccc(C(C)(C)C)cc5)cc5c6c(ccc(c7c(Oc8ccc(C(C)(C)C)cc8)cc(c2c37)C1=O)c64)C(=O)N([R])C5=O</smiles>

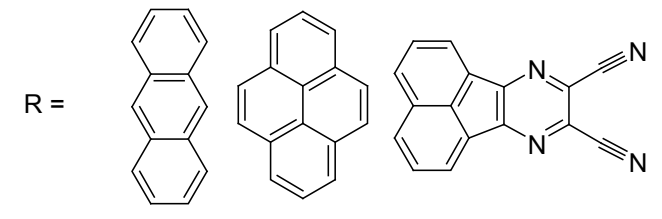

10

11

12
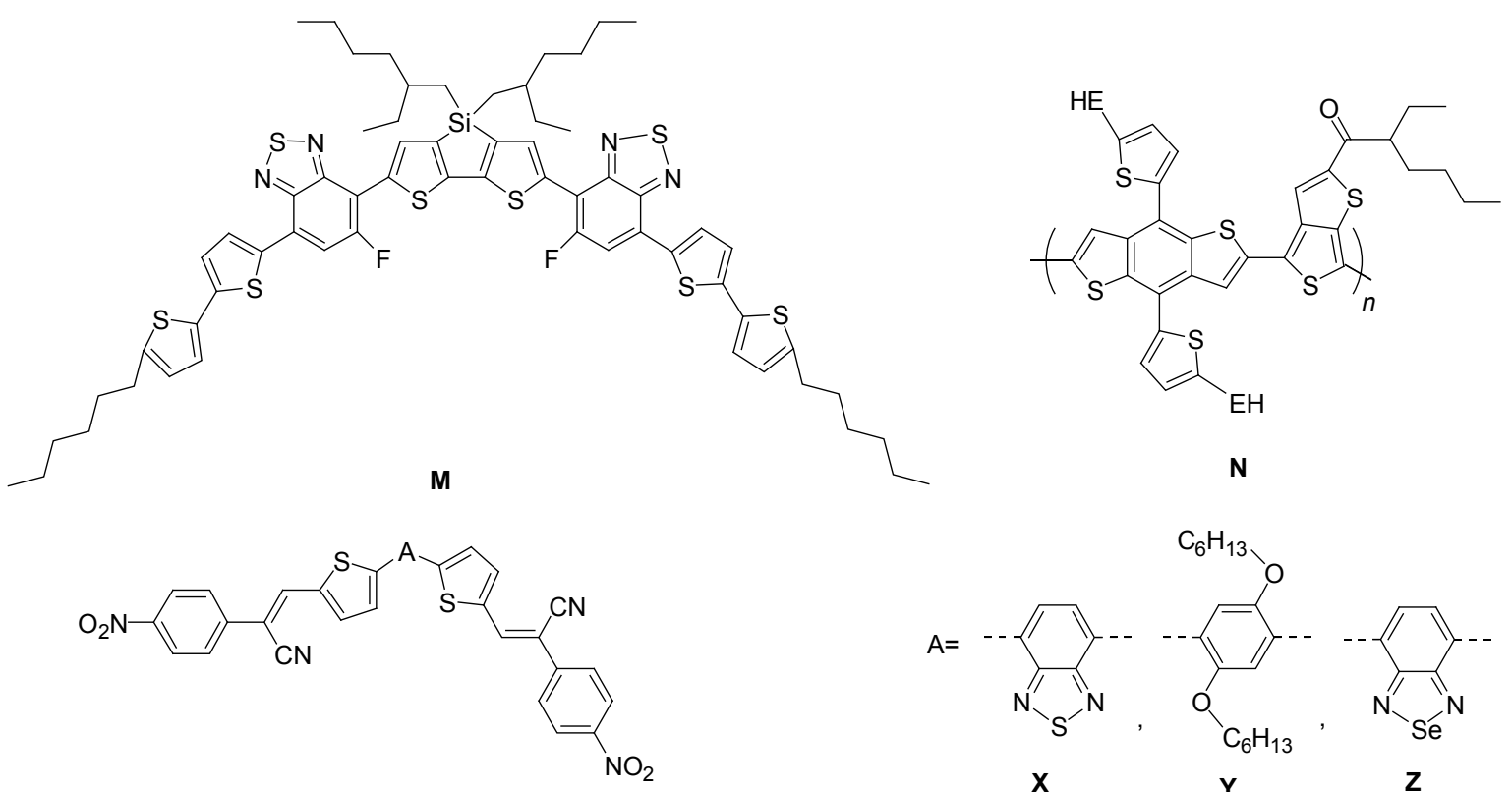

图 2 酰亚胺及其衍生物小分子电子受体材料的化学结构

Figure 2 Chemical structures of rylene diimide-based acceptors

表 1 酰亚胺类小分子 $n$-型电子受体材料在 OPV 器件中的光伏性能

Table 1 Photovoltaic properties of rylene diimide-based acceptors

\begin{tabular}{|c|c|c|c|c|c|c|}
\hline Acceptor & Blend & $\mathrm{HOMO} / \mathrm{LUMO} / \mathrm{eV}$ & $J_{\mathrm{sc}} /\left(\mathrm{mA} \cdot \mathrm{cm}^{-2}\right)$ & $V_{\mathrm{oc}} / \mathrm{V}$ & $\mathrm{FF} / \%$ & $\mathrm{PCE} / \%$ \\
\hline 1 & P3HT $: 1(1 ： 4)$ & $-5.82 /-3.69$ & 0.21 & 0.25 & 22 & 0.01 \\
\hline 2 & P3HT : $2(1: 4)$ & $-5.8 /-3.8$ & 1.49 & 0.48 & 35 & 0.25 \\
\hline 2 & $\mathbf{M}: \mathbf{2}(1: 1)$ & $-5.8 /-3.8$ & 7.4 & 0.78 & 52 & 3.0 \\
\hline 3 & P3HT $: 3(1: 1)$ & - & 1.74 & 0.75 & 38 & 0.50 \\
\hline 4 & P3HT $: 4(1: 2)$ & $-5.79 /-3.73$ & 2.95 & 0.60 & 52 & 0.91 \\
\hline 5 & P3HT $: 5(1: 1)$ & $-5.55 /-3.63$ & 2.86 & 0.67 & 50 & 0.96 \\
\hline 6 & 钯酞菁 & $-6.2 /-3.9$ & 5 & - & 63 & 2.0 \\
\hline 7 & 钯酞菁 & - & 5 & - & 40 & 1.0 \\
\hline $9 a$ & $\mathbf{N}: \mathbf{9 a}(1: 1)$ & $-5.65 /-3.84$ & 8.86 & 0.85 & 54.1 & 4.03 \\
\hline $9 b$ & P3HT $: 9 b(2.5 ： 1)$ & $-5.48 /-3.84$ & 5.69 & 0.68 & 50.0 & 1.93 \\
\hline 10 & $\mathbf{X}: \mathbf{1 0}(1: 1)$ & $-6.0 /-3.85$ & 6.8 & 0.88 & 47 & 2.85 \\
\hline 11 & $\mathbf{Y}: \mathbf{1 1}(1: 3.5)$ & $-5.9 /-3.8$ & 6.3 & 0.95 & 53 & 3.17 \\
\hline 12 & $\mathbf{Z}: \mathbf{1 2}(1: 1)$ & $-5.90 /-3.95$ & 8.30 & 0.90 & 52 & 3.88 \\
\hline 13a & P3HT : 13a $(1: 1)$ & $-5.53 /-4.05$ & 3.43 & 0.82 & 53 & 1.5 \\
\hline $13 b$ & P3HT $: \mathbf{1 3 b}(1: 2)$ & $-5.83 /-4.12$ & 0.81 & 0.83 & 34 & 0.19 \\
\hline $13 \mathrm{c}$ & P3HT : 13c (1:3) & $-5.60 /-4.14$ & 0.45 & 0.64 & 33 & 0.09 \\
\hline
\end{tabular}


制作 OPV 器件, 通过对器件结构的优化, 提高了内量子 效率(IQE), 使其转化效率达到了 $3 \%$, 成为非富勒烯电 子受体材料领域突破性的进展之一.

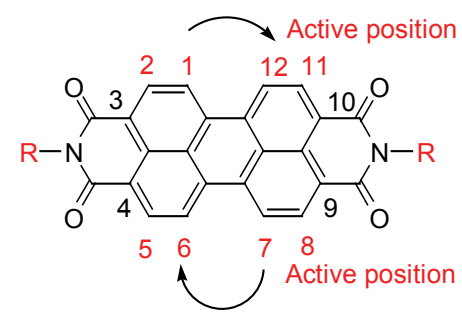

图 3 菲酰亚胺核的活性位置

Figure 3 The active position of perylenediimide core

通过对 PDI 核的活性位进行烷基化修饰, 可以在高 沸点溶剂中明显地调节其固态的光物理性质, 使得 PDI 更有利于成为 OPV 器件的 $n$-型电子受体材料 ${ }^{[30,31]}$. Sharma 等 ${ }^{[32]}$ 则在 PDI 核的 $1,7(6,12)$ 位上引入了芳香环 (化合物 4, 5), 这样的分子结构在聚集时产生了更有效 的 $\pi-\pi$ 堆积, 在与 P $3 \mathrm{HT}$ 的器件测试中, 转化效率分别达 到了 $0.91 \%$ 和 $0.96 \%$.

Jabbour 课题组 ${ }^{[33]}$ 合成了菲酰亚胺衍生物 $(6 \sim 8)$, 并 作为 $n$-型电子受体材料, 采用钯酞菁(palladium phthalocyanine)作为 $p$-型电子给体材料. 由于共混物可以得到 覆盖全波长可见光区域的吸收, OPV 的外量子吸收光谱 拓展到了 $400 \sim 800 \mathrm{~nm}$ 的范围, 并且在 $600 \mathrm{~nm}$ 处达到了 最大外量子效率 $40 \%$ 左右, 所以化合物 6 8 与钯酞菁 共混的器件 PCE 分别达到了 $2.0 \%, 1.0 \%$ 和 $1.1 \%$. 其光 电性质的差异可能主要来源于化合物 $\mathbf{6}$ 与化合物 7 和 8 相比, OPV 器件存在较低的界面激子复合和较高的载流 子迁移率.

Zhang 和 Yao 等 ${ }^{[34,35]}$ 研究发现 PDI 材料的分子层次 纳米结构以及与电子给/受体材料混合形成的 $p-n$ 界面 性质, 如分子聚集尺度的大小、分子堆叠的有序性和 $\pi-\pi$ 堆叠的程度等, 会对器件性能产生重要影响. 这主要是 因为混合固态膜的吸收率、激子的扩散效率、激子的分 离效率、电子/空穴传输效率等这些性能参数很大程度上 都与分子材料的纳米结构密切相关. 通常 PDI 类材料具 有良好的光电性质, 但是分子之间过强的聚集性能导致 了混合膜大范围的聚集结构(通常超过 $100 \mathrm{~nm}$ ), 远大于 激子的有效扩散长度 $(20 \sim 30 \mathrm{~nm})$, 激子很容易陷于聚 集结构中, 从而导致了较低的 PCE. 因此, 若适当减小 PDI 材料的聚集能力, 一方面可以有助于激子扩散到界 面; 另一方面, 减小聚集结构势必可以增加 $p-n$ 界面的 接触面积，进而提高激子的分离效率.

为了适度抑制 PDI 材料聚集倾向, Zhang 等 ${ }^{[34]}$ 以噻 吩基团作为桥联, 设计了 “萠酰亚胺-噻吩一花酰亚胺” 结构的小分子 $(\mathbf{9 a})$, 与 $p$-型电子给体材料 $\mathbf{N}$ 以 $1: 1$ 混合 制作 OPV 器件, 其转化效率达到了 $4.03 \%$. 这是目前非 富勒烯小分子材料所得到的最高的 PCE. Yao 课题组 ${ }^{[35]}$
运用了同样的设计思想，将噻吩换为稠环噻吩基团，合 成了新的桥联 $n$-型电子受体材料(9b), 其 PCE 也达到了 $1.93 \%$.

Sharma 课题组 ${ }^{[36,37]}$ 通过引入叔丁基苯氧基合成了 一系列 PDI 衍生物, 展现出了优良的光伏特性. 在酰亚 胺上连接不同的稠环单元得到电子受体材料 $10 \sim 12$, 表现出良好的电子迁移率. 当化合物 $10 \sim 12$ 作为 $\mathrm{OPV}$ 器件电子受体材料, 进行退火处理并在活性层和阴极之 间加入 $\mathrm{ZnO}$ 层后, $\mathrm{PCE}$ 分别达到了 $2.85 \%, 3.17 \%$ 和 $3.88 \%$.

相对于菲酰亚胺(PDI)类材料，与其相似稠环结构 的萗酰亚胺(NDI)类材料由于能隙较宽、吸光范围难以 突破 $400 \mathrm{~nm}$ 等, 受到的关注较少. 但是近年来，也有一 些课题组在相关方向上取得了突破. Jenekhe 等 ${ }^{[38]}$ 将噻 吩单元引入 NDI 合成了一系列 $\pi$ 共轭的 $p-n$ 结构衍生物 13a 13c. 此类衍生物表现出较窄的能隙 $(2.1 \sim 1.4 \mathrm{eV})$, 其 LUMO 能级数值在 $-4.0 \mathrm{eV}$ 左右, 而 $\mathrm{HOMO}$ 能级数 值则介于 -5.5 到 $-6.1 \mathrm{eV}$ 之间, 这说明可以与常见的 $p$-型给体材料构成所需的能级差, 来驱动电荷转移. $\mathrm{XRD}(\mathrm{X}$ 射线衍射分析)测试以及分子结构模拟的结果说 明了 13a 具有较好的平面结构, 分子堆叠为面对面的 $\pi-\pi$ 堆叠, 分子间距离很短 $(0.321 \sim 0.326 \mathrm{~nm})$, 有利于激 子的有效分离, 并表现出良好的电子迁移率, OPV 转换 效率达 $1.5 \%$.

\section{2 并五苯及其衍生物小分子电子受体材料}

并五苯及其衍生物易于通过化学修饰调控薄膜形 态，以提高电荷传输速率，使得此类衍生物成为提高 OPV 器件性能的理想电子受体材料 ${ }^{[39]}$. Anthony 等 ${ }^{[39]}$ 报 道了一系列有拉电子基团 $\left(\mathrm{CN}, \mathrm{CF}_{3}\right)$ 修饰的并五苯衍生 物. 强的拉电子基团可以使并五苯材料降低其 LUMO 能级, 从而使并五苯结构衍生物从富电子材料转变为缺 电子受体材料(如图 4 所示). 使用甲苯/二氯苯(10:3)为 溶剂, 与 P3HT 按 1: 1 配比条件下, 衍生物 14, 15 的 OPV 器件的 PCE 都达到了 $1.3 \%$, 但是衍生物 16 的 PCE 只有 $0.8 \%$. 相关研究结果显示衍生物 14 和 15 具有 “夹 心人字形” 晶体堆叠结构, 提高了电子传输性能, 对器 件性能产生了重要影响.

Wang 等 ${ }^{[40]}$ 报道了一种新型有机电子受体材料喹叫啶酮(QA)及其衍生物. 它们具有出色的化学稳定 性和热稳定性, 独特的超分子组装特性及其优异的光电 性能. 基于分子内电荷转移(ICT)和 QA 固体聚集时丰富 的分子间相互作用，可以高效吸收可见光. 未修饰的 QA 分子水溶性较差，但对其 $\mathrm{N}$ 原子经简单的烷基化可 以有效提高其溶解度, 使之转化为可溶液加工的有机电 子材料 ${ }^{[41,42]} .7 \mathbf{a} \sim 17 \mathbf{c}$ 具有低的能隙 $(1.8 \mathrm{eV})$ 和低的 LUMO 能级 $(-4.1 \mathrm{eV})$, 与 P3HT 按 $1: 1$ 混合制作的本 体异质结 OPV 器件, 17c 的 PCE 达到了 $1.57 \%$, 而 $17 \mathrm{a}$ 


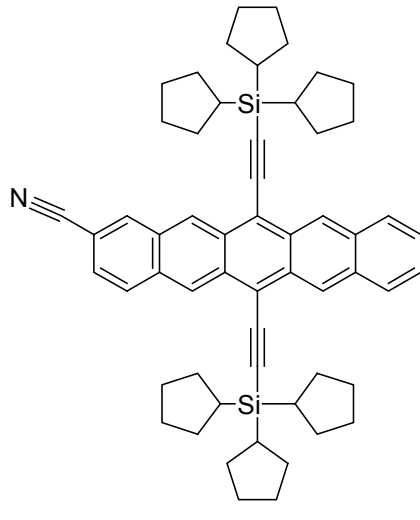

14

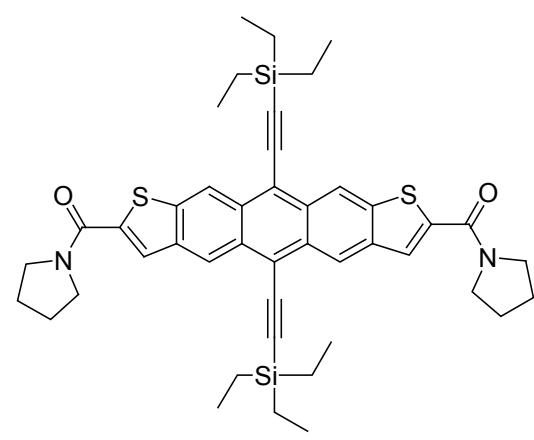

16<smiles>CC(C)CS(C#Cc1c2cc3ccccc3cc2c(C#CS(CC(C)C)(CC(C)C)CC(C)C)c2cc3ccccc3cc12)(CC(C)C)CC(C)C</smiles>

15<smiles>[R]N1c2ccccc2C(=C(C#N)C#N)c2cc3c(cc21)N([R])c1ccccc1C3=C(C#N)C#N</smiles>

17a: $R=$ butyl

17b: $R=$ hexyl

17c: $R=$ octyl

图 4 并五苯及其衍生物小分子电子受体材料的化学结构

Figure 4 Chemical structures of pentacene-based acceptors

和 $17 \mathbf{b}$ 只有 $0.28 \%$ 和 $0.30 \%$. 这主要因为 $17 \mathbf{c}$ 较长的烷 基取代链, 使其拥有了较好的柔韧性, 在分子排列和聚 集时拥有更好的聚集状态，而有利于激子的分离和载流 子的输运, 进而表现出更好的器件性能. 表 2 列出了以 上并五苯类 $n$-型电子受体材料在 OPV 器件中的光伏性 能.

强拉电子基团修饰后的并五苯衍生物, 在 OPV 器 件中会获得优良的开路电压 $\left(V_{\mathrm{oc}}\right)$, 甚至优于一些富勒烯 受体材料. 通过炔硅基 $\left(-\mathrm{C} \equiv \mathrm{C}-\mathrm{Si}-\mathrm{R}_{3}, \mathrm{R}\right.$ 为烷基链或 环戊烷)修饰分子结构, 优化分子空间构型, 会增强分 子间 $\pi-\pi$ 堆叠, 使其 OPV 器件具有更高的 $V_{\mathrm{oc}}$.

\section{3 苯噻唑及其衍生物小分子电子受体材料}

苯噻唑小分子衍生物在制作 OPV 器件过程中, 可 以采用真空蒸镀, 也可以溶液旋涂得到无定形薄膜, 经
进一步退火处理, 则可得到高度有序的薄膜获得良好的 电子传输性能. 目前, 苯噻唑小分子衍生物作为电子受 体材料在 OPV 器件中表现出较大的潜力 ${ }^{[43]}$, 逐渐受到 人们的关注(如图 5 所示).

Burn 等 ${ }^{[4]}$ 将苯噻唑与芴(三聚噻吩衍生物), 双氧乙 烯(DCV)结合在一起，合成了非富勒烯小分子电子受体 材料 18(19), 它们不仅可以通过真空蒸镀也可以通过溶 液法加工，得到无定形薄膜; 在温和的温度下进行退火 处理，可以使薄膜具有更好的有序性，同时增强了其电 荷传输特性. 实验测得它们的 LUMO 能级分别为 -3.6 $\mathrm{eV}$ 和 $-3.7 \mathrm{eV}$ ，与 $\mathrm{PC}_{60} \mathrm{BM}$ 相当. 两种分子都可以与 P3HT 发生明显的荧光淬灭现象，而且时间分辨微波电 导率测试也通过移动电荷验证了激子分离的产生. 化合 物 18 和 19 的 PCE 分别为 $0.73 \%$ 和 $1.43 \%$.

表 2 并五苯及其衍生物小分子电子受体材料在 OPV 器件中的光伏性能

Table 2 Photovoltaic properties of pentacene-based acceptors

\begin{tabular}{lcccccc}
\hline Acceptor & Blend & HOMO/LUMO/eV & $J_{\mathrm{sc}} /\left(\mathrm{mA}^{\bullet} \mathrm{cm}^{-2}\right)$ & $V_{\mathrm{oc}} / \mathrm{V}$ & $\mathrm{FF} / \%$ & $\mathrm{PCE} / \%$ \\
\hline $\mathbf{1 4}$ & P3HT $: \mathbf{1 4}(1: 1)$ & $-5.29 /-3.50$ & 3.72 & 0.84 & 41 & 1.29 \\
$\mathbf{1 5}$ & P3HT $: \mathbf{1 5}(1: 1)$ & - & 3.17 & 0.80 & 50 & 1.26 \\
$\mathbf{1 6}$ & P3HT $: \mathbf{1 6}(5: 3)$ & $-5.34 /-3.21$ & - & - & - & 0.09 \\
$\mathbf{1 7}$ & P3HT $: \mathbf{1 7 a}(1: 1)$ & $-5.75 /-4.00$ & 1.45 & 0.40 & 48 & 0.28 \\
$\mathbf{1 7 b}$ & P3HT $: \mathbf{1 7 b}(1: 1)$ & $-5.80 /-4.00$ & 1.43 & 0.42 & 49 & 0.30 \\
$\mathbf{1 7} \mathbf{c}$ & P3HT $: \mathbf{1 7 c}(1: 1)$ & $-5.90 /-4.10$ & 5.72 & 0.48 & 57 & 1.57 \\
\hline
\end{tabular}



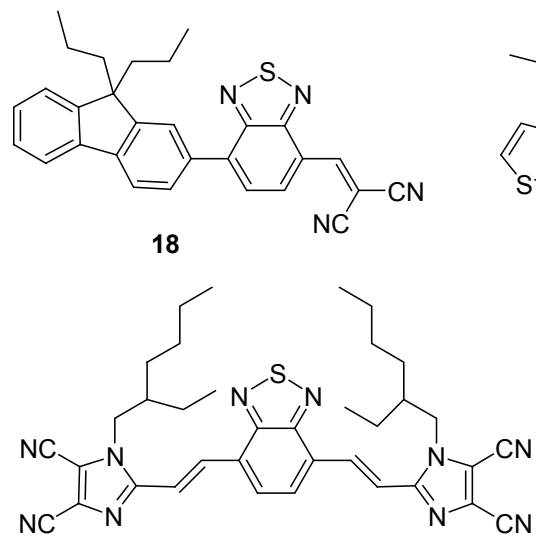

20
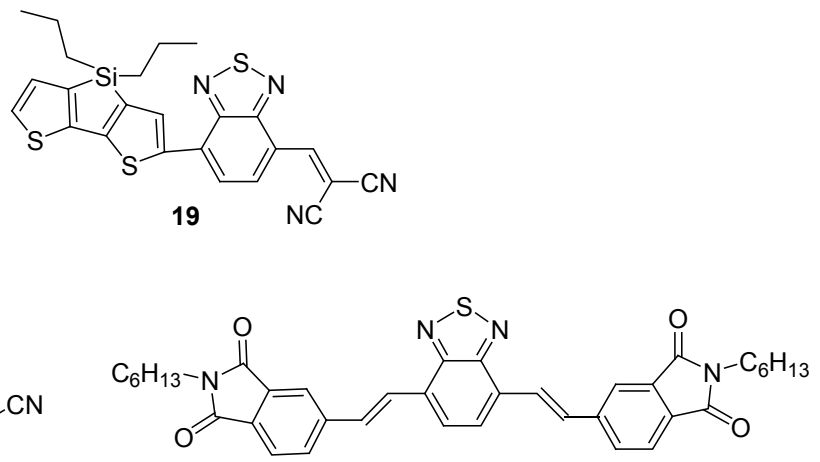

21

图 5 苯噻唑及其衍生物小分子电子受体材料的化学结构

Figure 5 Chemical structures of benzothiadiazole-based acceptors

表 3 苯噻唑及其衍生物小分子电子受体材料在 OPV 器件中的光伏性能

Table 3 Photovoltaic properties of benzothiadiazole-based acceptors

\begin{tabular}{clccccc}
\hline Acceptor & Blend & HOMO/LUMO/eV & $J_{\mathrm{sc}} /\left(\mathrm{mA}^{\bullet} \mathrm{cm}^{-2}\right)$ & $V_{\mathrm{oc}} / \mathrm{V}$ & $\mathrm{FF} / \%$ & $\mathrm{PCE} / \%$ \\
\hline $\mathbf{1 8}$ & P3HT $: \mathbf{1 8}(1: 2)$ & $-6.2 /-3.6$ & 5.7 & 0.62 & 50 & 1.4 \\
$\mathbf{1 9}$ & P3HT $: \mathbf{1 9}(1: 1.5)$ & $-5.4 /-3.7$ & 4.85 & 0.54 & 54.7 & 1.43 \\
$\mathbf{2 0}$ & P3HT $: \mathbf{2 0}(1: 1.4)$ & $-6.0 /-3.4$ & 1.9 & 0.77 & 11 & 0.73 \\
$\mathbf{2 1}$ & P3HT $: \mathbf{2 1}(1: 1.4)$ & $-5.8 /-3.3$ & 4.7 & 0.96 & 41 & 0.12 \\
\hline
\end{tabular}

Sellinger 课题组 ${ }^{[45,46]}$ 为了增强电子受体基团(A)的 电子传输性能, 引入了咪唑和乙烯基酰亚胺的吸电子基 团(B), 形成了新型 B-A-B 的电子受体结构, 它们较之 $\mathrm{PC}_{60} \mathrm{BM}$ 有更宽的吸收波长, 衍生物 $\mathbf{2 0 , 2 1}$ 的 LUMO 能 级数值为 $-3.43 \mathrm{eV},-3.30 \mathrm{eV}$, 相对于 $\mathrm{PC}_{60} \mathrm{BM}$, 可以 获得更大的开路电压 $\left(V_{\mathrm{oc}}\right)$. 衍生物 21 的 OPV 器件转换 效率达 $2.54 \%$. 这是目前苯噻唑衍生物电子受体材料获 得的最高 PCE. 表 3 列出了苯噻唑及其衍生物小分子电 子受体材料在 OPV 器件中的光伏性能.

亲电基团苯噻唑已在 D-A 结构的电子给体聚合物 和小分子中得到广泛研究. 在小分子受体领域, 苯噻唑 基团也可以作为桥联基团, 通过连接不同亲电能力的基 团(如芴基, 氰基等)来调整个分子的吸电子能力和能隙, 仍具有较大的优化空间.

\section{4 吡咯并吡咯二酮(DPP)及其衍生物小分子电子受 体材料}

近年来, 可溶液加工的窄带隙吡咯并吡咯二酮 (DPP)衍生物, 展现出优良的有机半导体性质. 在引入 强吸电子基团(比如醛基，三氟甲基，三氟苯基等)后， 也可以作为小分子 OPV 电子受体材料 ${ }^{[47,48]}$. 图 6 列出了 部分典型的吡咯并吡咯二酮衍生物电子受体材料.

Janssen 等 ${ }^{[47]}$ 制备了基于 DPP 的 OPV 小分子 $n$-型衍 生物 22 与 23 . 化合物 $22 \mathrm{~b}$ 与 $23 \mathrm{~b}$ 相比于 $22 \mathrm{a}$ 与 $23 \mathrm{a}$ 具 有较低的还原电位, 而氧化电位则相当. 由于溶解性的 差异, OPV 器件制作时, 22a 与 23b 使用氯仿为溶剂, 22b 与 23a 则使用氯苯为溶剂, 并经过热退火处理. 但由于
填充因子和开路电压较低, 其器件的 PCE 并不理想, 介 于 $0.15 \% \sim 0.31 \%$ 之间.

与此同时, Sonar 课题组 ${ }^{[48]}$ 也报道了一系列基于 DPP 结构的小分子 $n$-型衍生物. 通过在 DPP 结构中引入 三氟甲苯基和三氟苯基等强吸电子基团，合成了一系列 可溶性窄带隙的 $n$-型电子受体材料 24 27(如图 6). 此 类化合物的 HOMO 能级介于 $-5.18 \sim-5.31 \mathrm{eV}$ 之间, LUMO 能级介于 $-3.52 \sim-3.68 \mathrm{eV}$ 之间, 带隙则介于 $1.81 \sim 1.94 \mathrm{eV}$ 之间, 吸收范围覆盖了 $300 \sim 700 \mathrm{~nm}$. 如 此优良的光电性质主要是由于富电子的亚苯基(亚噻吩 基)与拉电子基团 DDP 核之间发生了有效的电荷转移. 与 P3HT 按 2:1 的比例制作 OPV 器件, 最高 PCE 为 $1.00 \%$. 其中, 化合物 24 具有最高的 PCE 转化效率, 其 具有更好的分子平面结构, 在成膜过程中有更好的 $\pi-\pi$ 堆叠效应, 更有利于激子的分离以及电荷的传输.

由于三苯胺分子存在 $\mathrm{sp}^{3}$ 轨道杂化, 具有特殊的星 型分子结构. 当共轭分子与其结合形成 $\pi$ 共轭结构的星 状分子时, 具有良好的电子传输性能和光学各向同性. Zhan 课题组 ${ }^{[49]}$ 合成了以三苯胺分子为核, DPP 基团为臂 的新型星状受体分子, 其 $\mathrm{OPV}$ 器件的转化效率达到了 $1.2 \%$. 在 DPP 类材料中, 这样突出的 PCE 主要是由于化 合物 28 与给体材料 P3HT 的共混层形成了尺度较理想 的晶粒, 增强了薄膜的有序性和电子传输能力. 表 4 汇 总了部分典型的 DPP 类小分子 $n$-型电子受体材料在 OPV 器件中的光伏性能. 


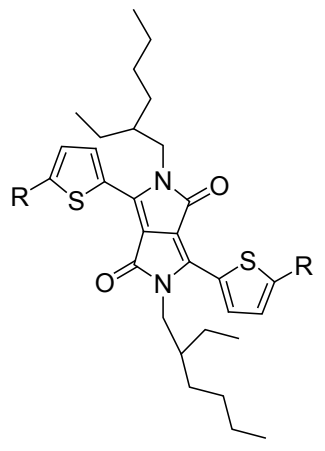

22a: $\mathrm{R}=\mathrm{H}$

22b: $\mathrm{R}=\mathrm{CHO}$<smiles>CCCCCCCCN1C(=O)C2=C(c3ccc(-c4ccc(C(F)(F)F)cc4)s3)N(CCC)C(=O)C2=C1c1ccc(-c2ccc(C(F)(F)F)cc2)s1</smiles>

24

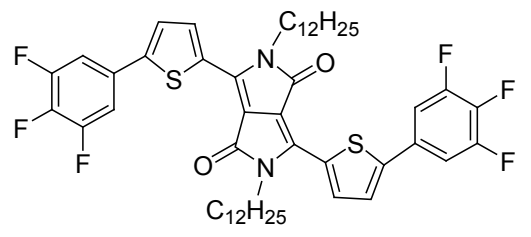

26

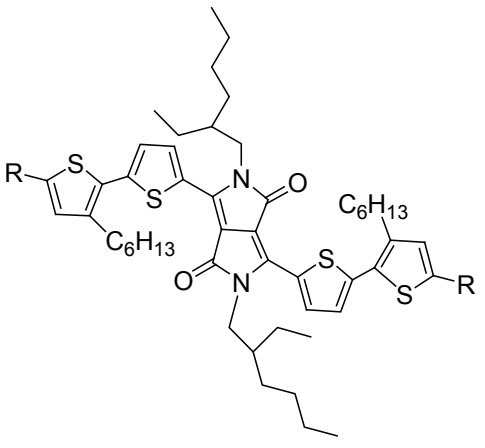

23a: $\mathrm{R}=\mathrm{H}$

23b: $\mathrm{R}=\mathrm{CHO}$<smiles>CCCCCCCCN1C(=O)C2=C(c3ccc(-c4cc(C(F)(F)F)cc(C(F)(F)F)c4)s3)N(CCC)C(=O)C2=C1c1ccc(-c2cc(C(F)(F)F)cc(C(F)(F)F)c2)s1</smiles>

25<smiles>CCCCCCCCCN1C(=O)C2=C(c3ccc(/C=C/c4ccc(C(F)(F)F)cc4)s3)N(CCCC)C(=O)C2=C1c1ccc(/C=C/c2ccc(C(F)(F)F)cc2)s1</smiles>

27

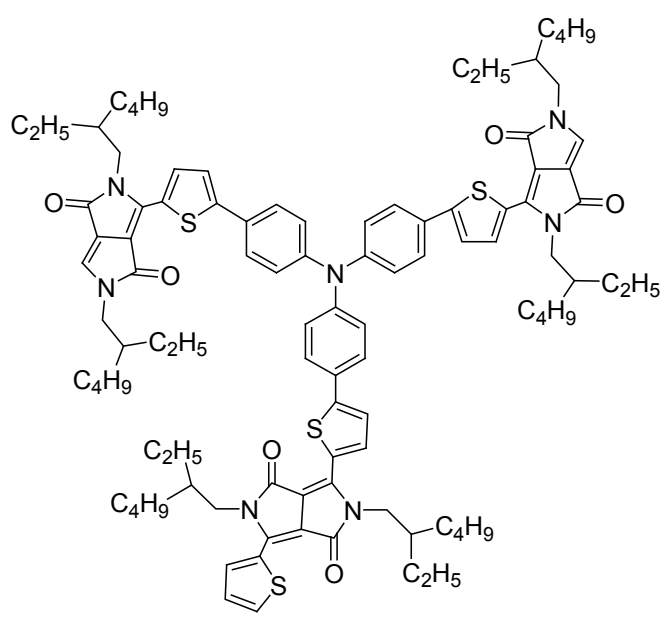

28

图 6 吡咯并吡咯二酮及其衍生物电子受体材料的化学结构

Figure 6 Chemical structures of DPP-based acceptors

表 4 吡咯并吡咯二酮(DPP)及其衍生物小分子电子受体材料在 OPV 器件中的光伏性能

Table 4 Photovoltaic properties of DPP-based acceptors

\begin{tabular}{|c|c|c|c|c|c|c|}
\hline Acceptor & Blend & $\mathrm{HOMO} / \mathrm{LUMO} / \mathrm{eV}$ & $J_{\mathrm{sc}} /\left(\mathrm{mA} \cdot \mathrm{cm}^{-2}\right)$ & $V_{\mathrm{oc}} / \mathrm{V}$ & $\mathrm{FF} / \%$ & $\mathrm{PCE} / \%$ \\
\hline $22 a$ & P3HT $: 22 a(1 ： 1.5)$ & $-5.55 /-3.59$ & 0.79 & 0.85 & 25 & 0.17 \\
\hline $22 b$ & P3HT $: 22 \mathbf{b}(1 ： 1)$ & $-5.90 /-4.09$ & 1.93 & 0.52 & 31 & 0.31 \\
\hline $23 \mathbf{a}$ & P3HT $:$ 23a $(1 ： 2)$ & $-5.39 /-3.68$ & 0.87 & 0.85 & 32 & 0.24 \\
\hline 23b & P3HT $: \mathbf{2 3 b}(1: 2)$ & $-5.54 /-3.94$ & 0.86 & 0.60 & 29 & 0.15 \\
\hline 24 & P3HT : $24(1: 2)$ & $-5.26 /-3.52$ & 2.36 & 0.81 & 52 & 1.00 \\
\hline 25 & P3HT : $25(1 ： 2)$ & $-5.28 /-3.57$ & 0.85 & 0.71 & 23 & 0.14 \\
\hline 26 & P3HT : $26(1 ： 2)$ & $-5.31 /-3.68$ & 2.70 & 0.71 & 32 & 0.56 \\
\hline 27 & P3HT : $27(1 ： 2)$ & $-5.18 /-3.55$ & 1.70 & 0.64 & 53 & 0.58 \\
\hline 28 & P3HT : $27(1: 1)$ & $-5.26 /-3.26$ & 2.68 & 1.18 & 38 & 1.20 \\
\hline
\end{tabular}


DPP 基团具有优异的电化学性质、机械加工性能和 热力学稳定性, 可以满足制作有机电子器件的要求. 取 代基的不同会直接影响整个分子的 $\pi-\pi$ 堆叠和固态光物 理性质. 所以通过篮选适合的拉电子取代基, 会有效提 高 DPP 衍生物小分子受体材料的光电转化性能.

\section{5 芴基衍生物小分子电子受体材料}

芴基衍生物在有机电致发光(OLED)和有机激光领 域得到了广泛研究, 并展现出了优良的电子传输性能和 光电性质 ${ }^{[00,51]}$. 对于 $\mathrm{OPV}$ 小分子受体材料而言, 䓄基衍 生物的 LUMO 能级与给体材料(如 P3HT)比较匹配, 可 以有效降低给受体之间 LUMO 能级差带来的能量损失. 如何通过对芴基骨架结构进行修饰并使之成为具有拉 电子能力的小分子 $n$-型电子受体材料, 成为人们关注的 新焦点.

双烯芴的 $\mathrm{C}$ 原子之间存在 $\mathrm{sp}^{2}$ 杂化, 提供了一个平 面离域结构, 类似于 PCBM. 并且这样的双烯芴结构很 容易接受一个电子, 使其中一个芴环成为 14 个 $\pi$ 电子的 芳香环. 因此也有成为有机太阳能电池电子受体材料的 潜力 $^{[52]}$. 图 7 列出了部分典型的芴基衍生物小分子 $n$-型
电子受体材料.

Wudl 课题组 ${ }^{[2]}$ 报道了 9,9-双烯芴的结构, 并引入 了烷氧基进行结构修饰, 得到了新型的 OPV 小分子 $n$ 型电子受体材料 29. 该材料 $\mathrm{HOMO}$ 能级为 $-5.30 \mathrm{eV}$, LUMO 能级为 $-3.12 \mathrm{eV}$. 与 P $3 \mathrm{HT}$ 按 $1.5: 1$ 混合, 使用 $\mathrm{Al}$ 做阴极得到的器件效率为 $0.36 \%$; 而用 $\mathrm{Ba}$ 做阴极时 则达到 $1.70 \%$. 其中 OPV 器件性能上的差异可能是由于 阴极材料功函数的不同而引起的. 当 $\mathrm{Al}$ 的功函数 $(-4.26 \mathrm{eV})$ 低于化合物 29 的 LUMO 能级 $(-3.12 \mathrm{eV})$ 时, 费米(Fermi) 能级由于阴极的禁锢, 能量在电子转移到阴 极的过程中损失. 只有当阴极的功函数接近 LUMO 能 级 $(-3.12 \mathrm{eV})$ 时, 来自阴极的电子转移才能通过费米能 级. Hwang 课题组 ${ }^{[53]}$ 设计并合成了线型 9,9-双烯芴的结 构衍生物 30, 器件的转化效率为 $0.26 \%$, 说明增加芴的 结构单元并未能有效增强材料的光电转换性能.

Tilley 等 ${ }^{[4]}$ 制备了全 $\mathrm{F}$ 取代的锗芴并与强吸电子基 团六氟苯炔偶联得到了结构新颖的 $n$-型电子受体材料 31. $\mathrm{OPV}$ 器件表现出较高的开路电压 $0.90 \mathrm{~V}, \mathrm{PCE}$ 为 $0.035 \%$. Tian 等 ${ }^{[55]}$ 合成了具有 $p-n$ 结构的咔唑衍生物 32,

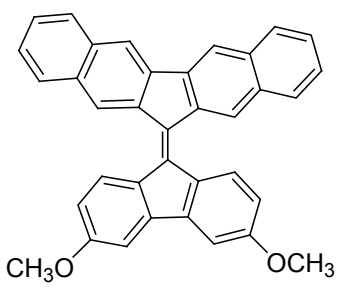

29<smiles>Fc1c(F)c(F)c(C#Cc2c(F)c(F)c3c(c2F)[Ge]c2c(F)c(F)c(C#Cc4c(F)c(F)c(F)c(F)c4F)c(F)c2-3)c(F)c1F</smiles>

31

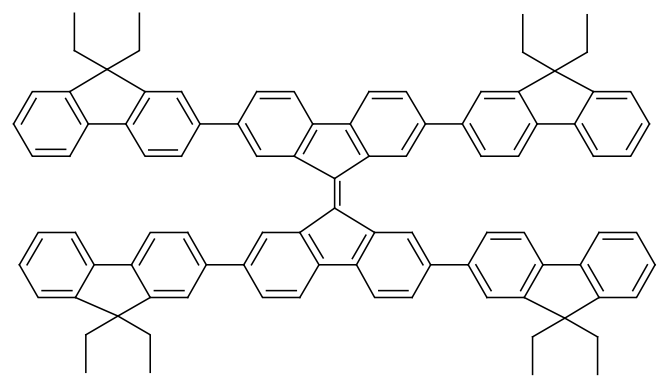

30<smiles>CC1(C)CC(=C(C#N)C#N)CC(C=Cc2ccc3[nH]c4ccc(C=CC5CC(=C(C#N)C#N)CC(C)(C)C5)cc4c3c2)C1</smiles>

32

$\mathrm{C}_{3} \mathrm{H}_{7}$

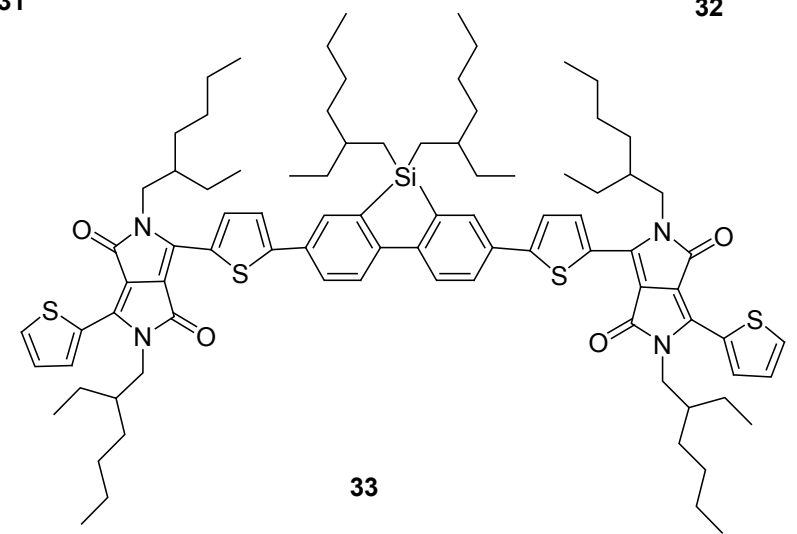

图 7 芴及其衍生物小分子电子受体材料的化学结构

Figure 7 Chemical structures of fluorene-based acceptors 
迁移率较低, 只有 $1.15 \times 10^{-5} \mathrm{~cm}^{2} \cdot \mathrm{V}^{-1} \cdot \mathrm{s}^{-1}$ (相对于 $\mathrm{PC}_{60} \mathrm{BM}\left(2.0 \times 10^{-3} \mathrm{~cm}^{2} \cdot \mathrm{V}^{-1} \cdot \mathrm{s}^{-1}\right)$, 器件 $\mathrm{PCE}<1 \%$.

二苯并噻咯(DBS)中的噻咯基团具有共轭特性, 由 于硅碳之间 $\sigma^{*}$ 轨道杂化形成的 $\pi^{*}$ 轨道具有较低的 LUMO 能级, 同时噻咯基团也具有良好的电子传输性 能和分子平面结构. Lin 等 ${ }^{[56]}$ 合成了 DBS 与双 DPP 结构 单元的新型 $n$-型电子受体材料 33. 与 P3HT 按 $1: 1.2$ 比例混合制作 OPV 器件 (溶剂退火), 其转化效率达 $2.05 \%$. 如表 5 所示, 列出了部分典型的芴基衍生物小 分子 $n$-型电子受体材料在 OPV 器件中的光伏性能.

\section{6 荧葱稠环酰亚胺及其衍生物电子受体材料}

Pei 课题组 ${ }^{[57]}$ 对荧葱稠环酰亚胺结构, 在 OPV 小分 子受体材料领域进行了深入的研究和探索. 合成了一系 列苂蒽稠环酰亚胺衍生物(如图 8 所示). 使用 P3HT 作为 给体材料, 并且通过对器件制作过程的优化, 使得该类 材料的最高器件效率达到了 $2.89 \%$. 表 6 列举出了部分 典型荧蒽稠环酰亚胺衍生物小分子 $n$-型电子受体材料 在 OPV 器件中的光伏性能.
通过原子力显微镜 (AFM) 和 $X$ 射线光电子能谱 (XPS)对上述衍生物活性层表面构型的研究, 发现衍生 物 34 39 与 P3HT 共混的活性层具有相似的表面粗糙 度和表面成分. 这是由于上述衍生物都具有相同的苂葱 稠环酰亚胺骨架, 只是在取代基团上做了较小的改变导 致的。但通过 X-射线衍射(XRD)测试，对比各衍生物不 同的衍射强度, 说明各衍生物活性层的 P3HT 结晶度不 尽相同，进而导致了各活性层具有不同的传输能力. 进 一步通过迁移率测试(SCLC)发现衍生物 36 具有最高的 空穴迁移率, 这也解释了衍生物 36 具有最高 $J_{\mathrm{sc}}$ 的原因, 其他衍生物的空穴迁移率高低也同样与各自器件的 $J_{\mathrm{sc}}$ 大小成正比，这样的差异最终导致了不同苂蒽稠环酰亚 胺衍生物 OPV 器件具有不同的 PCE.

这说明了活性层形貌对荧蒽稠环酰亚胺类材料在 OPV 器件中的性能有着决定性的影响作用, 通过分子 设计优化活性层形貌成为提高器件空穴传输能力和 PCE 的重要途径.

表 5 芴基衍生物小分子电子受体材料在 OPV 器件中的光伏性能

Table 5 Photovoltaic properties of fluorene-based acceptors

\begin{tabular}{ccccccc}
\hline Acceptor & Blend & HOMO/LUMO/eV & $J_{\mathrm{sc}} /\left(\mathrm{mA}^{\bullet} \mathrm{cm}^{-2}\right)$ & $V_{\mathrm{oc}} / \mathrm{V}$ & $\mathrm{FF} / \%$ & \multicolumn{1}{c}{$\mathrm{PCE} / \%$} \\
\hline $\mathbf{2 9}$ & P3HT $: \mathbf{2 8}(1.5: 1)$ & $-5.17 /-3.24$ & 3.9 & 1.10 & 40 & 1.70 \\
$\mathbf{3 0}$ & P3HT $: \mathbf{2 9}(1: 0.4)$ & $-5.81 /-3.49$ & 1.20 & 0.70 & 30 & 0.26 \\
$\mathbf{3 1}$ & P3HT $: \mathbf{3 0}(1: 1)$ & $-6.5 /-3.2$ & 0.211 & 0.905 & 18.4 & 0.035 \\
$\mathbf{3 2}$ & MEH-PPV $: \mathbf{3 1}(1: 1)$ & $-5.47 /-3.42$ & 0.68 & 1.14 & 25 & 0.19 \\
$\mathbf{3 3}$ & P3HT $: \mathbf{3 2}(1.2: 1)$ & $-5.30 /-3.28$ & 4.91 & 0.97 & 43 & 2.05 \\
\hline
\end{tabular}

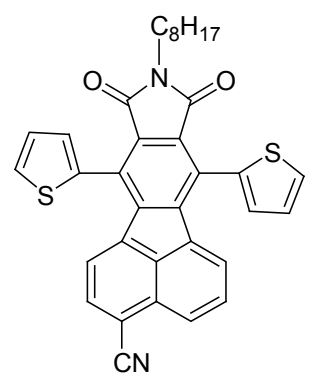

34

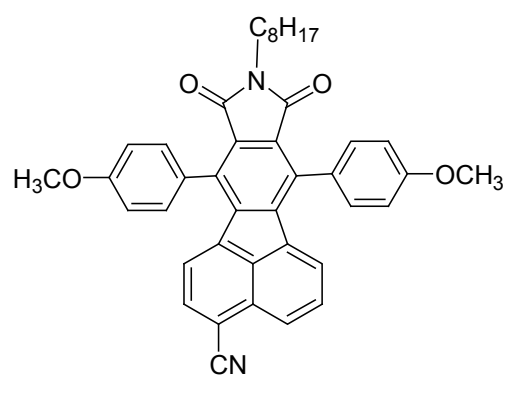

37<smiles></smiles>

35

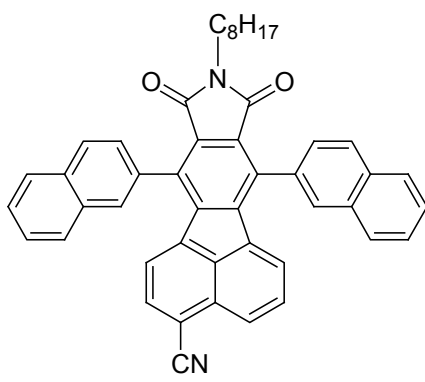

38

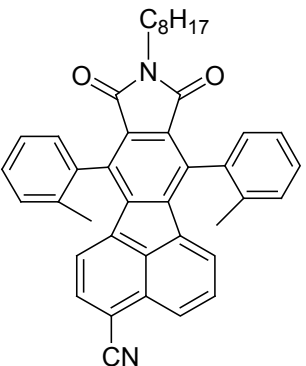

36

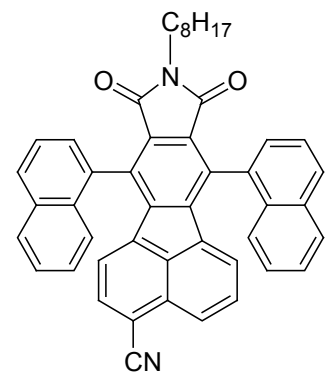

39

图 8 苂葱稠环酰亚胺及其衍生物电子受体材料

Figure 8 Chemical structures of fluoranthene-fused imide-based acceptors 
表 6 苂葱稠环酰亚胺衍生物小分子电子受体材料在 OPV 器件中的光伏性能

Table 6 Photovoltaic properties of fluoranthene-fused imide-based acceptors

\begin{tabular}{ccccccc}
\hline Acceptor & Blend & $\mathrm{HOMO} / \mathrm{LUMO} / \mathrm{eV}$ & $J_{\mathrm{sc}} /\left(\mathrm{mA} \cdot \mathrm{cm}^{-2}\right)$ & $V_{\text {oc }} / \mathrm{V}$ & $\mathrm{FF} / \%$ & $\mathrm{PCE} / \%$ \\
\hline $\mathbf{3 4}$ & P3HT $: \mathbf{3 4}(1: 1)$ & $-6.23 /-3.48$ & 4.83 & 0.88 & 53 & 2.25 \\
$\mathbf{3 5}$ & P3HT $: \mathbf{3 5}(1: 1)$ & $-5.24 /-3.43$ & 5.60 & 0.96 & 49 & 2.61 \\
$\mathbf{3 6}$ & P3HT $: \mathbf{3 6}(1: 1)$ & $-6.27 /-3.44$ & 6.35 & 0.95 & 48 & 2.89 \\
$\mathbf{3 7}$ & P3HT $: \mathbf{3 7}(1: 1)$ & $-6.04 /-3.40$ & 4.63 & 0.96 & 48 & 2.12 \\
$\mathbf{3 8}$ & P3HT $: \mathbf{3 8}(1: 1)$ & $-6.15 /-3.43$ & 5.85 & 0.94 & 47 & 2.58 \\
$\mathbf{3 9}$ & P3HT $: \mathbf{3 9}(1: 1)$ & $-6.12 /-3.43$ & 4.59 & 0.93 & 49 & 2.11 \\
\hline
\end{tabular}

\section{7 寡聚噻吩及其衍生物电子受体材料}

与酞菁铜和并五苯一样, 寡聚噻吩也被广泛采用作 为 $\mathrm{OPV}$ 的 $n$-型电子受体材料. 同时, 噻吩-S,S-二氧化物 衍生物在寡聚噻吩体系里可以显著提高电子亲和 能 ${ }^{[58 \sim 62]}$. Barbarella 课题组 ${ }^{[00,61]}$ 合成了线型及 $\mathrm{V}$ 型支链 的噻吩-S,S-二氧化物衍生物小分子 $n$-型材料 40 与 41 (如 图 9 所示). 线型化合物 $\mathbf{4 0}$ 由于其晶型和聚集状态减小 了 $p-n$ 界面, 其 $\mathrm{OPV}$ 器件的 PCE 转化效率只有 $0.06 \%$; V 型支链化合物 41 相对于线型化合物 $\mathbf{4 0}$ 展现出较低的结 晶度和较好的表面构型, 所以经退火处理后其转化效率 达 $0.3 \% \sim 0.4 \%$.

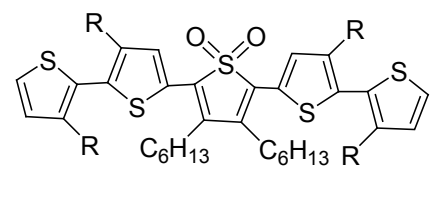

40

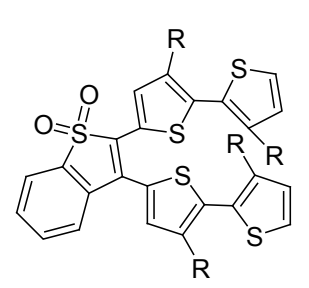

41

图 9 寡聚噻吩及其衍生物小分子电子受体材料的化学结构

Figure 9 Chemical structures of oligothiophene-based acceptors

但是此类小分子受体材料在与给体材料共混之后, 表现出的活性层形貌和电子传输性能并不理想. 提高此 类材料在 OPV 器件中的应用潜力, 仍需通过取代基对 分子结构进行修饰, 改善其成膜和电子传输性能.

\section{3 总结与展望}

OPV 器件效率与器件寿命在过去的十几年中取得 了快速发展, 这应归功于对于器件结构更加深入的理解 和认识, 以及电子给/受体材料的不断发展. 富勒烯类电 子受体材料在 OPV 领域中研究较为成熟, 而对于非富 勒烯小分子电子受体材料而言, 目前的器件性能尚不理 想. 事实上, 在已报道的非富勒烯小分子材料中, 只有 少数材料的 PCE 超过 $4 \%$. 然而, 此类材料由于性能上 的优势, 已经受到了越来越多的关注, 也有更多的研究
试图从这个方向挑战富勒烯材料的化学与物理极限.

总体而言，非富勒烯小分子电子受体材料的设计和 开发需要以下几方面的考量: (1)窄能隙的设计, 以具有 高的消光系数和宽的光谱吸收范围; (2)较长的激子扩散 长度, 使激子能够迁移到达 $p$ - $n$ 界面; (3)较高的 LUMO 能级, 获得高的 $V_{\mathrm{oc}}$; (4)能够延长电荷分离状态, 从而增 强电子的收集 ${ }^{[62]}$. 当然, 制约非富勒烯小分子材料的主 要问题还是活性层的构型和电子传输性能. 虽然这类材 料在薄膜测试时, 展现出优良的电子迁移率, 但是与给 体材料混合之后, 迁移率普遍不高. 这可能是由于活性 层较强的聚集状态而影响了激子的传输和分离效果. 所 以对 $p-n$ 界面更深入的理解和认识, 会对提高 OPV 器件 效率产生重要影响. 目前而言, 桥型结构和多维结构的 非富勒烯小分子材料的设计, 具有解决迁移率和 $p-n$ 界 面聚集问题的潜力, 可以有效提升整体器件性能, 这也 是非富勒烯小分子电子受体材料值得关注的发展方向.

\section{作者简介}

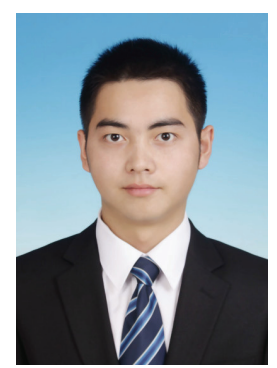

付钰, 自 2011 年 9 月起加入南京邮电大学信息材料与纳 米技术研究院从事硕士研究工作. 他的研究涉及有机太阳能 电池新型给受体材料的制备与性能研究, 目前其主要研究方 向为非富勒烯小分子 OPV 受体材料的合成与性能研究.

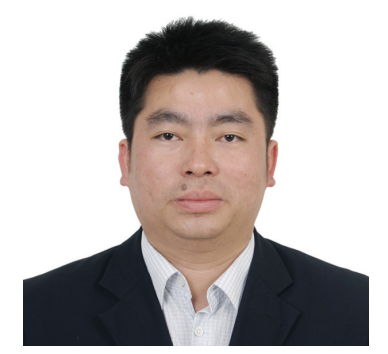

赖文勇, 南京邮电大学教授, 博士生导师; 主要从事有机 光电子学、塑料电子材料与器件等领域的研究工作. 973 青年 
科学家(2013)、教育部新世纪优秀人才(2013)、江苏省 “杰出 青年” 基金获得者(2013)、江苏省 “333 高层次人才培养工程” 中青年科学技术带头人(2013)、江苏省 “六大人才高峰” 高层 次人才培养对象(A 类)(2012)、江苏省 “青蓝工程” 中青年学 术带头人(2012)、优秀青年骨千教师(2010); 南京邮电大学 “青 年科技之星” (2011)、“鼎新学者” (2012)、“鼎山学者” (2013); 江苏省大学生物理竞赛优秀指导教师(2012). 相关成果获江苏 省科技进步奖二等奖(2008)、江苏省科学技术奖二等奖(2012, 第二完成人)、国家自然科学奖二等奖( 2013 , 第二完成人).

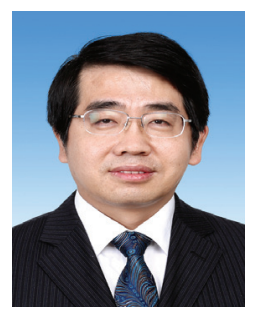

黄维, 汉族, 1965 年 5 月生于河北. 1983 年 8 月参加工作, 1987 年 6 月加入中国共产党. 北京大学毕业, 研究生学历, 1992 年 1 月获得理学博士学位. 博士生导师, 中国科学院院士 (信息技术科学部), 中央组织部“千人计划” 国家特聘专家, 国 家科学技术部“973”项目首席科学家, 国家教育部“长江学 者” 特聘教授, 国家自然科学基金委员会 “杰出青年基金” 获 得者, 享受国务院“政府特殊津贴”。作为第一完成人获国家 自然科学奖二等奖(2013)、江苏省科学技术奖一等奖(2010)等 多项国家级/省部级以上奖励.

\section{References}

[1] Gratzel, M. In Organic Electronics, Vol. 4, Eds.: Huang, W.; Mi, B. M.; Gao, Z. Q., Science Press, Beijing, 2011, p. 217.

[2] (a) Li, Z. F.; Peng, Q.; He, P.; Wang, Y. L.; Hou, Q. F.; Li, B. L.; Tian, W. J. Chin. J. Org. Chem. 2012, 32, 834. (李在房, 彭强, 和 平, 王艳玲, 侯秋飞, 李本林, 田文晶, 有机化学, 2012, 32, 834.) (b) Liu, X.; Chen, C.; He, R.; Shen, W.; Li, M. Acta Chim. Sinica 2012，70，2365. (刘小锐, 陈春香, 何荣幸, 申伟, 李明, 化学学 报, 2012, 70, 2365.) (c) Li, X.; Zhao, B.; Cao, Z.; Shen, P.; Tan, S. Acta Chim. Sinica 2012, 70, 2433. (李新炜, 赵斌, 曹镇财, 沈平, 谭松庭，化学学报, 2012, 70, 2433.) (d) Zou, W.; Liu, Y.; Jia, Q.; Ge, Z. Chin. J. Org. Chem. 2013, 33, 1522. (邹文武, 刘颖, 贾庆 明, 葛子义, 有机化学, 2013, 33, 1522.)

[3] Huang, W.; Yu, W.-L.; Meng, H.; Pei, J.; Li, S. F. Y. Chem. Mater. 1998, $10(11), 3340$.

[4] Yu, W.-L.; Meng, H.; Pei, J.; Huang, W. J. Am. Chem. Soc. 1998, 120(45), 11808.

[5] Yu, W. L.; Meng, H.; Pei, J.; Huang, W.; Li, Y. F.; Heeger, A. J. Macromolecules 1998, 31, 4838.

[6] Sariciftci, N. S.; Smilowitz, L.; Heeger, A. J.; Wudl, F. Science 1992, $258,1474$.

[7] Mihailetchi, V. D.; Xie, H.; De Boer, B.; Koster, L. J. A.; Blom, P. W. M. Adv. Funct. Mater. 2006, 16, 699.

[8] Lin, Y.; Li, Y.; Zhan, X. Chem. Soc. Rev. 2012, 41, 4245.

[9] Chamberlain, G. A. Sol. Cells 1983, 8, 47.

[10] Yu, G.; Gao, J.; Hummelen, J. C.; Wudl, F.; Heeger, A. J. Science 1995, 270, 1789.

[11] Tang, C. W. Appl. Phys. Lett. 1986, 48, 183.

[12] Lunt, R. R.; Giebink, N. C.; Belak, A. A.; Benziger, J. B.; Forrest, S. R. J. Appl. Phys. 2009, 105, 053711.

[13] Hiramoto, M.; Fujiwara, H.; Yokoyama, M. J. Appl. Phys. 1992, 72, 3781.

[14] Taima, T.; Chikamatsu, M.; Yoshida, Y.; Saito, K.; Yase, K. Appl. Phys. Lett. 2004, 85, 6412.

[15] Sariciftci, N. S.; Smilowitz, L.; Heeger, A. J.; Wudl, F. Science 1992, 258,1474

[16] (a) You, J.; Dou, L.; Yoshimura, K.; Kato, T.; Ohya, K.; Moriarty, T.; Emery, K.; Chen, C. C.; Gao, J.; Li, G.; Yang, Y. Nat. Commun. 2013, 4, 1446. (b) He, Z.; Zhong, C.; Su, S.; Xu, M.; Wu, H.; Cao, Y.
Nature Photonics 2012, 6, 593. (c) He, Z.; Zhong, C.; Huang, X.; Wong, W. Y.; Wu, H.; Chen, L.; Su, S.; Cao, Y. Adv. Mater. 2011, 23, 4636.

[17] Perez, M. D.; Borek, C.; Forrest, S. R.; Thompson, M. E. J. Am. Chem. Soc. 2009, 131, 9281.

[18] Scharber, M. C.; Mühlbacher, D.; Koppe, M.; Denk, P.; Waldauf, C.; Heeger, A. J.; Brabec, C. J. Adv. Mater. 2006, 18, 789.

[19] Reese, M. O.; Nardes, A. M.; Rupert, B. L.; Larsen, R. E.; Olson, D. C.; Lloyd, M. T.; Shaheen, S. E.; Ginley, D. S.; Rumbles, G.; Kopidakis, N. Adv. Funct. Mater. 2010, 20, 3476.

[20] Anthony, J. E.; Facchetti, A.; Heeney, M.; Marder, S. R.; Zhan, X. Adv. Mater. 2010, 22, 3876.

[21] Mishra, A.; Bauerle, P. Angew Chem. Int. Ed. 2012, 51, 2020.

[22] Wen, Y.; Liu, Y. Adv. Mater. 2010, 22, 1331.

[23] Zhan, X.; Facchetti, A.; Barlow, S.; Marks, T. J.; Ratner, M. A.; Wasielewski, M. R.; Marder, S. R. Adv. Mater. 2011, 23, 268.

[24] Wurthner, F. Chem. Commun. (Camb). 2004, 1564.

[25] Wurthner, F.; Stolte, M. Chem. Commun. 2011, 47, 5109.

[26] Bhosale, S. V.; Jani, C. H.; Langford, S. J. Chem. Soc. Rev. 2008, 37, 331.

[27] Van-Bavel, S. S.; Sourty, E.; de With, G.; Loos. J. Nano Lett. 2009, 9, 507.

[28] Kamm, V.; Battagliarin, G.; Howard, I. A.; Pisula, W.; Mavrinskiy, A.; Li, C.; Mullen, K.; Laquai, F. Adv. Energy Mater. 2011, 1, 297.

[29] Sharenko, A.; Proctor, C. M.; van der Poll, T. S.; Henson, Z. B.; Nguyen, T. Q.; Bazan, G. C. Adv Mater. 2013, 25, 4403.

[30] Dou, C.; Wang, C.; Zhang, H.; Gao, H.; Wang, Y. Chemistry 2010, 16, 10744 .

[31] Kim, I.; Haverinen, H. M.; Wang, Z.; Madakuni, S.; Li, J.; Jabbour, G. E. Appl. Phys. Lett. 2009, 95, 023305.

[32] Sharma, G. D.; Suresh, P.; Mikroyannidis, J. A.; Stylianakis, M. M. J. Mater. Chem. 2010, $20,561$.

[33] Kim, I.; Haverinen, H. M.; Wang, Z.; Madakuni, S.; Li, J.; Jabbour, G. E. Appl. Phys. Lett. 2009, 95, 023305

[34] Zhang, X.; Lu, Z.; Ye, L.; Zhan, C.; Hou, J.; Zhang, S.; Jiang, B.; Zhao, Y.; Huang, J.; Liu, Y.; Shi, Q.; Yao, J. Adv. Mater. 2013, 25, 5791.

[35] Jiang, B.; Zhang, X.; Zhan, C.; Lu, Z.; Huang, J.; Ding, X.; He, S.; Yao, J. Polym. Chem. 2013, 4, 4631.

[36] Sharma, G. D.; Suresh, P.; Mikroyannidis, J. A.; Stylianakis, M. M. J. Mater. Chem. 2010, 20, 561.

[37] Mikroyannidis, J. A.; Suresh, P.; Sharma, G. D. Synth. Met. 2010, 160,932 .

[38] Ahmed, E.; Ren, G.; Kim, F. S.; Hollenbeck, E. C.; Jenekhe, S. A. Chem. Mater. 2011, 23, 4563 .

[39] Shu, Y.; Lim, Y.-F.; Li, Z.; Purushothaman, B.; Hallani, R.; Kim, J. E.; Parkin, S. R.; Malliaras, G. G.; Anthony, J. E. Chem. Sci. 2011, 2, 363.

[40] Zhou, T.; Jia, T.; Kang, B.; Li, F.; Fahlman, M.; Wang, Y. $A d v$. Energy Mater. 2011, 1, 431

[41] Gross, E. M.; Anderson, J. D.; Slaterbeck, A. F.; Thayumanavan, S.; Barlow, S.; Zhang, Y.; Marder, S. R.; Hall, H. K.; Nabor, M. F.; Wang, J. F.; Mash, E. A.; Armstrong, N. R.; Wightman, R. M. J. Am. Chem. Soc. 2000, 122, 4972.

[42] Dou, C.; Wang, C.; Zhang, H.; Gao, H.; Wang, Y. Chem. Eur. J. 2010, 16, 10744

[43] Fang, Y.; Pandey, A. K.; Nardes, A. M.; Kopidakis, N.; Burn, L. P.; Meredith, P. Adv. Energy Mater. 2013, 3, 54.

[44] Schwenn, P. E.; Gui, K.; Nardes, A. M.; Krueger, K. B.; Lee, K. H.; Mutkins, K.; Rubinstein, D. H.; Shaw, P. E.; Kopidakis, N.; Burn, P. L.; Meredith, P. Adv. Energy Mater. 2011, 1, 73.

[45] Shin, R. Y. C.; Kietzke, T.; Sudhakar, S.; Dodabalapur, A.; Chen, Z. K.; Sellinger, A. Chem. Mater. 2007, 19, 1892.

[46] Ooi, Z. E.; Tam, T. L.; Shin, R. Y. C.; Chen, Z. K.; Kietzke, T.; Sellinger, A.; Baumgarten, M.; Mullen, K.; deMello, J. C. J. Mater. Chem. 2008, 18, 4619 .

[47] Karsten, B. P.; Bijleveld, J. C.; Janssen, R. A. J. Macromol. Rapid Commun. 2010, 31, 1554.

[48] Sonar, P.; Ng, G.-M.; Lin, T. T.; Dodabalapur, A.; Chen, Z.-K. J. Mater. Chem. 2010, 20, 3626.

[49] (a) Lin, Y.; Cheng, P.; Li, Y.; Zhan, X. Chem. Commun. (Camb) 2012, 48, 4773. (b) Shang, H.; Fan, H.; Liu, Y.; Hu, W.; Li, Y.; Zhan, X. Adv. Mater. 2011, 23, 1554

[50] (a) Lai, W. Y.; He, Q. Y.; Zhu, R.; Chen, Q. Q.; Huang, W. Adv. Funct. Mater. 2008, 18, 265. (b) Lai, W. Y.; Xia, R. D.; He, Q. Y.; Peter, A. L.; Huang, W.; Bradley, D. D. C. Adv. Mater. 2009, 21, 
355. (c) Lai, W.-Y.; Zhu, R.; Fan, Q.-L.; Hou, L.-T.; Cao, Y.; Huang, W. Macromolecules 2006, 39, 3707. (d) Lai, W. Y.; Chen, Q. Q.; He, Q. Y.; Fan, Q. L.; Huang, W. Chem. Commun. 2006, 18, 1959. (e) Lai, W. Y.; Liu, D.; Huang W. Macromol. Chem. Phys. 2011, 212, 445. (f) Xia, R. D.; Lai, W. Y.; Levermore, P. A.; Huang, W.; Bradley, D. D. C. Adv. Funct. Mater. 2009, 19, 2844. (g) Zhu. R.; Lai, W. Y.; Wang, H. Y.; Yu, N.; Wei, W.; Peng, B.; Huang, W.; Hou, H. T.; Peng, J. B.; Cao, Y. Appl. Phys. Lett. 2007, 90, 141909.

[51] (a) Lai, W. Y.; Xia, R. D.; Bradley, D. D. C.; Huang, W. Chem. Eur. J. 2010, 16, 8471. (b) Lai, W. Y.; Liu, D.; Huang, W. Sci. China Chem. 2010, 53, 2472. (c) Zhao, L.; Jiu, Y.; Wang, J.; Zhang, X.; Lai, W.; Huang, W. Acta Chim. Sinica 2013, 71, 1248. (赵玲玲, 酒 元达, 王建云, 张新稳, 赖文勇, 黄维, 化学学报, 2013, 71, 1248.)

[52] Gong, X.; Tong, M.; Brunetti, F. G.; Seo, J.; Sun, Y.; Moses, D.; Wudl, F.; Heeger, A. J. Adv. Mater. 2011, 23, 2272.

[53] (a) Park, O. Y.; Kim, H. U.; Kim, J.-H.; Park, J. B.; Kwak, J.; Shin, W. S.; Yoon, S. C.; Hwang, D.-H. Sol. Energy Mater. Sol. Cells 2013, 116, 275. (b) Kim, H. U.; Kim, J. H.; Suh, H.; Kwak, J.; Kim, D.; Grimsdale, A. C.; Yoon, S. C.; Hwang, D. H. Chem. Commun. (Camb.) 2013, 49, 10950
[54] Geramita, K.; McBee, J.; Tao, Y.; Segalman, R. A.; Tilley, T. D. Chem. Commun. 2008, 5107.

[55] Zhou, Y.; Pei, J.; Dong, Q.; Sun, X.; Liu, Y.; Tian, W. J. Phys. Chem. C 2009, 113, 7882

[56] Lin, Y.; Li, Y.; Zhan, X. Adv. Energy Mater. 2013, 3, 724.

[57] Zhou, Y.; Dai, Y. Z.; Zheng, Y. Q.; Wang, X. Y.; Wang, J. Y.; Pei, J. Chem. Commun. (Camb). 2013, 49, 5802.

[58] Barbarella, G.; Pudova, O.; Arbizzani, C.; Mastragostino, M.; Bongini, A. J. Org. Chem. 1998, 63, 1742.

[59] Barbarella, G.; Favaretto, L.; Sotgiu, G.; Zambianchi, M.; Antolini, L.; Pudova, O.; Bongini, A. J. Org. Chem. 1998, 63, 5497.

[60] Camaioni, N.; Ridolfi, G.; Fattori, V.; Favaretto, L.; Barbarella, G. Appl. Phys. Lett. 2004, 84, 1901.

[61] Ridolfi, G.; Favaretto, L.; Barbarella, G.; Samorì, P.; Camaioni, N. J. Mater. Chem. 2005, 15, 2220.

[62] Zhou, Y.; Ding, L.; Shi, K.; Dai, Y. Z.; Ai, N.; Wang, J.; Pei, J. $A d v$. Mater. 2012, 24, 957.

(Cheng, B.) 